\title{
Life in the groove: Re-visiting the common sense of sound reproduction
}

\author{
Kazuhiro Jo \\ Faculty of Design, Kyushu University / YCAM \\ Fukuoka / Yamaguchi, Japan \\ jo@jp.org
}

\author{
Paul DeMarinis \\ Stanford University \\ Palo Alto, CA \\ demarini@stanford.edu
}

\begin{abstract}
In this paper, we describe our project of "Life in the Groove," an attempt to re-examine the material and historical basis of sound reproduction. Through this paper, we would like to argue that the realities are more complex than the oft-told tales. We will re-visit the common sense of sound reproduction with the following three of our works of the project, "Groovular Synthesis - the Edison Effect revisited" - Paul DeMarinis (2019), "Au Clair de la Lune on Gramophone - For Édouard- Léon Scott and László Moholy- Nagy" - Kazuhiro Jo (1860/1923/2015), and "Mary Had a Little Lamb" - Paul DeMarinis and Kazuhiro Jo (2019)
\end{abstract}

Sound reproduction. Artworks. Media archaeology.

\section{INTRODUCTION}

In this paper, we describe our project of "Life in the Groove," an attempt to re-visit the common sense of sound reproduction. We would like to argue that the realities are more complex than such following oft-told tales.

- Alexander Graham Bell and Thomas Watson had their first telephone conversation in 1876. "Mr. Watson-Come here- I want to see you!" yelled Bell to Watson, and the world shook.

- Thomas Edison first heard his words"Mary had a little lamb"-(returned to him from the cylinder of a phonograph built by his assistants) in 1878.

- Guglielmo Marconi's wireless telegraph conquered the English Channel in1899. This is a bulleted list.

The problem of materially recorded traces constituting the "texts" of sounds is compounded not only by the rapid proliferation of such recordings which threatens to overtake the foreclose on sounds yet unheard in the form of bots as both producers and streamers of digital audio media, but also because, for the scholar or archaeologist of audio media, the authoritative first recording is a shifting and malleable target. Faint traces of long vanished sounds may exist anywhere, whether by intention or not. As Jonathan Stern noted, the oft-repeated stories of Bell, Edison and Marconi are powerful stories because they tell us that something happened to the nature, meaning, and practices of sound in the late nineteenth century. But they are incomplete. In both the cases, the inventors had a partially functional device before the moment of their "famous first." [Stern, 2003].

In addition, as Cox pointed, the inventions of such mechanical contraptions unwittingly disclosed aesthetic attention of not only to articulate sounds but also to have the noises, hum, hiss, and crackle of the apparatus themselves [Cox, 2018].

To be honest, such noisy, lo-fi sounds distant from our contemporary practices are the 'voice' of the inventions [Thompson, 2017]. The noises represent the medium and the means of sound reproduction's existence.

At the rest of paper, we will re-examine the material and historical basis of sound reproduction with the following three of our works of the project, which we have presented at the art track of RE:SOUND, the 8th International Conference on the Histories of Media Arts 2019 in Aalborg, Denmark.

- "Groovular Synthesis - the Edison Effect revisited" - Paul DeMarinis (2019)

- "Au Clair de la Lune on Gramophone - For Édouard- Léon Scott and László MoholyNagy" - Kazuhiro Jo (1860/1923/2015)

- "Mary Had a Little Lamb" - Paul DeMarinis and Kazuhiro Jo (2019) 
As a central emphasis of the project, we conceived to make maximal use of contemporary DIY and personal fabrication tools and techniques, including Arduino and Raspberry $\mathrm{Pi}$, 3D printing, laser cutting, as well as traditional methods of mold making, wax casting, hand painting, and soldering to engage the materiality of sound reproduction with the help of basic scientific principles of the photoelectric effect, mechanical vibration, and electromagnetic induction.

\section{2. "Groovular Synthesis - the Edison Effect reVisited" - Paul DeMarinis (2019)}

"Groovular Synthesis" was developed as part of "Life in the groove" during the period 2018-2019. The work is a combination of two related contraptions that play a single text as sounds. A spoken voice track is accompanied by another rendition in Morse-code. The Morse code groove was engraved on a brown wax Edison cylinder by a 15-watt blue laser controlled by an Arduino+MaxMSP patch. In keeping with the mythical symmetry of recording and reproduction, it is played back, with reference to the authors earlier work The Edison Effect (1989-1993) [Seiffarth and Beirer, 2011], by scanning the groove with a small red laser dot and using analog photo-pickups to decode the reflections into sounds. The plaintext itself resides on a black wax cylinder that is scanned by a small video camera and synchronized with a manipulated vocal recording of the same text. The black wax cylinder stands alone as an editioned work that may optionally be combined into the current configuration.

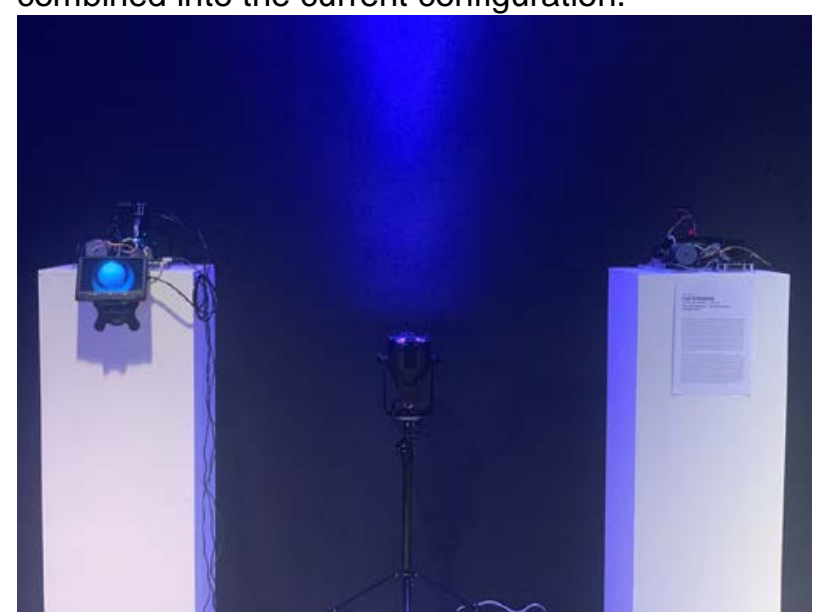

Figure 1: "Groovular Synthesis - the Edison Effect reVisited" - Paul DeMarinis (2019)

\section{Au Clair de la Lune - For Édouard-Léon Scott and László Moholy-Nagy - Kazuhiro Jo (1860/1923/2015) [Jo, 2018]}

I have suggested to change the gramophone from a reproductive instrument to a productive one, so that on a record without prior acoustic information, the acoustic information, the acoustic phenomenon itself originates by engraving the necessary Ritchriftreihen (etched grooves). [Moholy-Nagy, 1989]

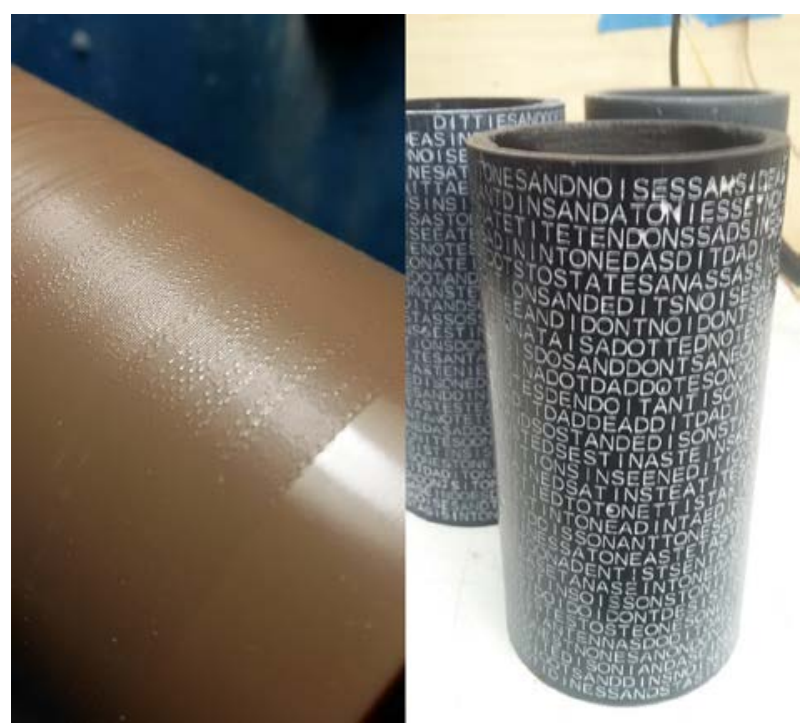

Figure 2: The Morse code groove engraved on a brown wax Edison cylinder (left) and the plaintext on a black wax cylinder(right)

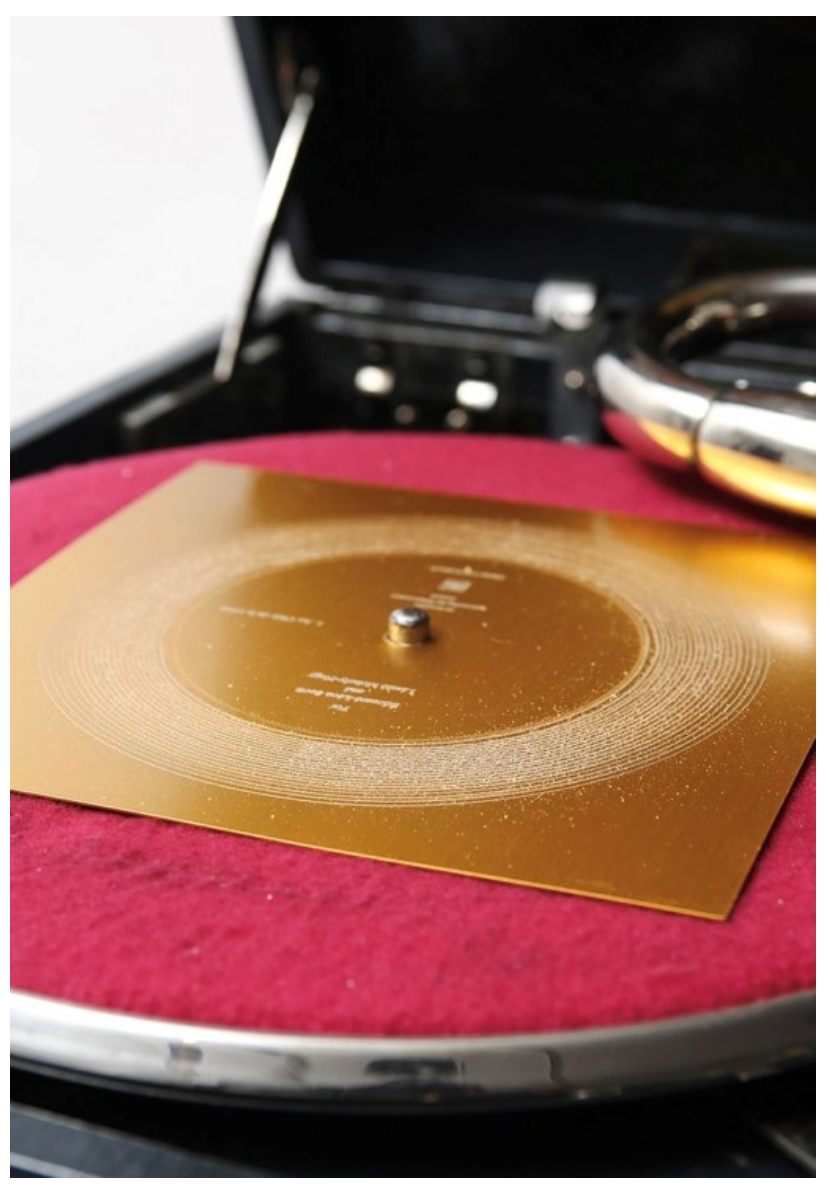

Figure 3: Au Clair de la Lune - For Édouard-Léon Scott and László Moholy-Nagy - Kazuhiro Jo (1860/1923/2015) (photo by Takeru Koroda). 
In 1923, Bauhaus master László Moholy-Nagy proposed to produce a record without inputting acoustic information. At the time, it was simply a provocative idea. However, after nine decades, we realize the idea on several materials, including paper, wood, and acrylic with the help of mature record players and current DIY digital tools such as a laser cutter or a cutting plotter.

An ordinary record works as follows. When people play a record, a stylus vibrates according to a groove and the vibration produce sounds. And, when people make a recording, the original sound vibrates the stylus and makes a groove.

However, in our approach, instead of using a recording of the music, we computationally drew a waveform with a conventional vector graphics application, Adobe Illustrator, by calculating the frequency of every note of the music. (Figure 4)

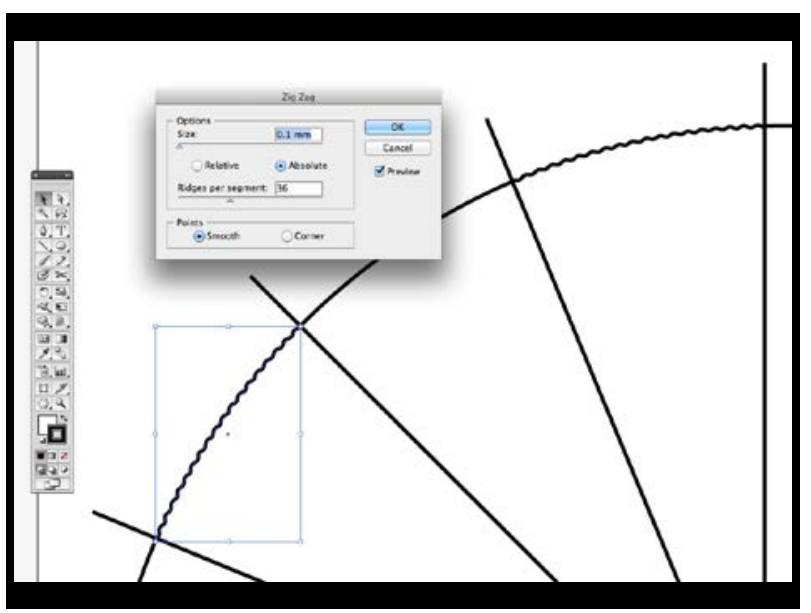

Figure 4: Computationally drew a waveform with Adobe Illustrator

In the artwork, we reproduced a French folk song, the oldest recorded music by Léon Scott, "Au Clair de la Lune," with the form of a record for a gramophone. Because of the weight of the soundbox of a gramophone, we used a lacquered anodized aluminium plate horizontally engraved by a laser cutter. The outcome could be played on conventional analogue record players in $78 \mathrm{rpm}$, including a traditional gramophone without any help of electricity.

\section{4. "Mary Had a Little Lamb" - Paul DeMarinis, Kazuhiro Jo (2019)}

The last artwork is "Mary Had a Little Lamb". Through history, people invented printing technologies in diverse ways. For example, in Asia, people started to print with woodblock or copper plate around 8th century [Kornicki, 2012]. In Europe, Gutenberg and others developed letterpress printing in the 15th century. In 1796 Alois Senefelder invented lithography, and in 1903, Ira Rubel developed the first commercial offset printing system. In 1969, Gary Starkweather invented the idea of the laser printer at the Xerox Webster Research Center and in 1984 Adobe systems produced PostScript in the market. With all printing technologies, the basic principle is the same, to put inks on a paper.

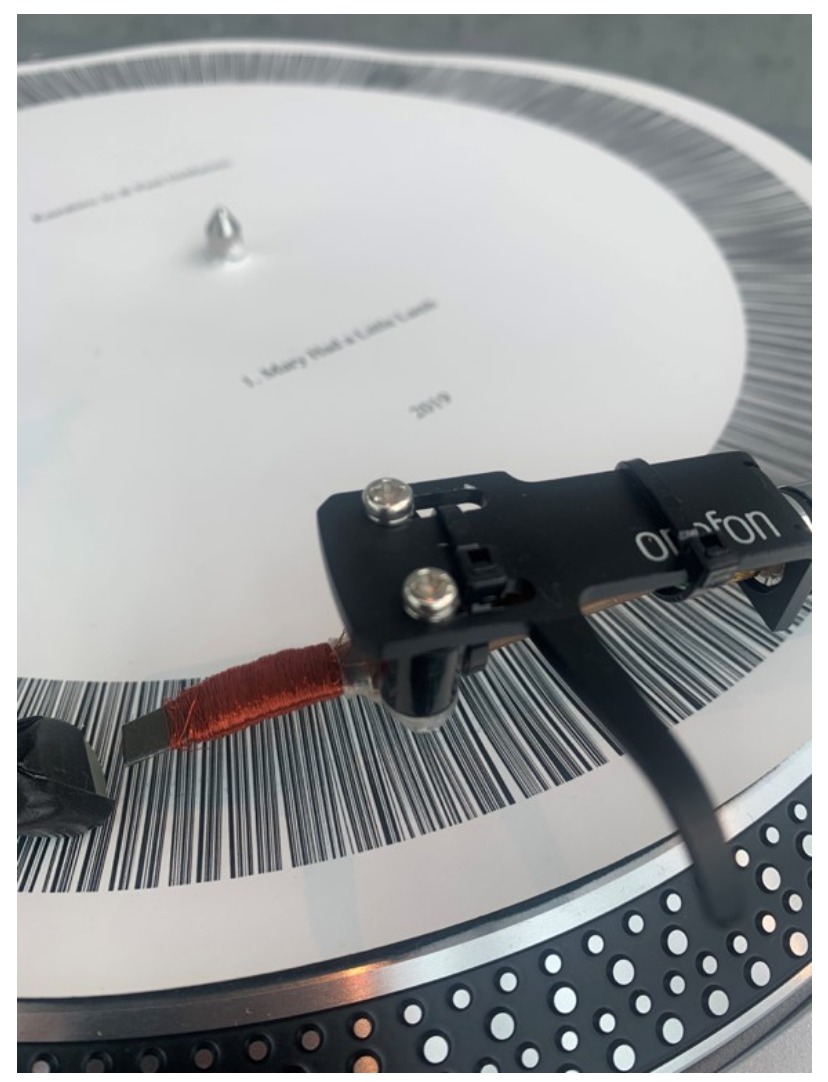

Figure 5: "Mary Had a Little Lamb" - Paul DeMarinis, Kazuhiro Jo (2019)

To realize the work "Mary had a little lamb," we combined the basic principle of printing technology with a simple physical phenomenon, electromagnetic induction. As Lenz depicted in his law in 1834, when a magnet moves around a coil, changes of a magnetic field induce an electric current in the wire of the coil.

With the principles, we actuate the strongest type of permanent magnet, neodymium, with calculated gaps of postscript print with a laser printer (Figure $6)$. We converted a waveform of PCM audio data into a 1-bit format with the help of BTc Sound Encoder [Black, 2009], and produced a series of black and white stripes in a circular shape with Adobe Illustrator. Then we print the result with a postscript laser printer. 


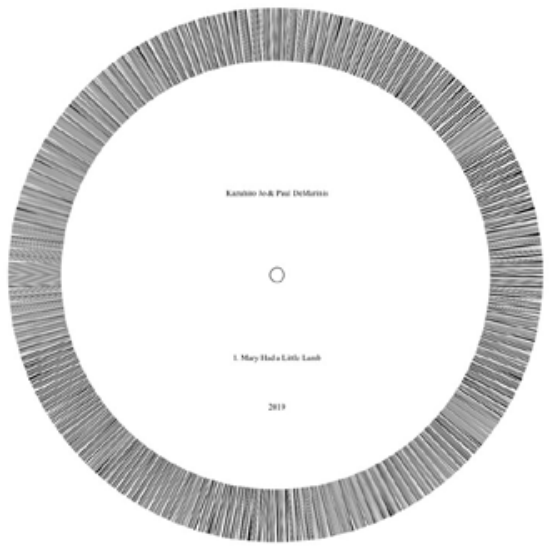

Figure 6: Calculated gaps of postscript print

As the sound source, we selected a voice as a particular case of sound - the renowned phrase of the Edison, "Mary had a little lamb", with one of the newest voices the non-existent voice of WaveNet, a deep neural network for generating raw audio waveforms [Oord et al, 2016].

The result might sound like a collection of collisions and frictions. However, once you know the sentence, "Mary had a little lamb," you cannot avoid making out the voice. It sounds like apophenia, where one imagines that one perceives a familiar pattern in random noise, however it's not.

This phenomenon calls to mind an early idea about the phonograph that Edison expressed to his friend Alfred Mayer.

\begin{abstract}
Another phenomenon I have noticed is that if two simple but different sentences are put on the machine, and a person who had never heard of such an apparatus be brought in and told to listen he will not even after a dozen repetitions be able to say what it is, but if the first sentence is told him \& then reproduced he generally says why that's perfect. The second sentence is now reproduced when he generally reads it or part of it the first time and the whole the second time if simple. The same thing has been noticed of the telephone, and I think it lack of confidence, or some obscure effect of the mind upon the hearing apparatus. They do not expect or imagine that a machine can talk hence cannot understand words. [Edison, 1878]
\end{abstract}

\section{Conclusion}

Each of these works stands in relation to the material and historical record of sound reproduction in a way that challenges the factuality of sound and the subjectivity of perception. Arrangements of apparatus, practices and reception position themselves in ever changing geometries. The current constellation of sound/recording/attention is subject to ever evolving practices and itself cannot be fixed.

\section{Acknowledgements}

Part of the work was supported by Stanford's Office of International Affairs, and JSPS KAKENHI Grant Number JP15K12842 and JP17H04772.

\section{REFERENCES}

Black, R. (2009) BTc Sound Encoder 3.0 Software, https://www.romanblack.com/picsound.htm (accessed September 13,z 2019)

Cox, C. (2018) Sonic Flux: Sound, Art, and Metaphysics. University of Chicago Press.

Edison, T. A. (1878) "Letter from Thomas Alva Edison to Alfred Marshall Mayer, February 11th, 1878," Edison Papers Digital Edition, http://edison.rutgers.edu/digital/document/X095A A. (accessed September 13, 2019)

Jo. K. (2018) Au Clair de la Lune on Gramophone "For Édouard-Léon Scott and László MoholyNagy" (1860 / 1923 / 2015). In Proceedings of the Twelfth International Conference on Tangible, Embedded, and Embodied Interaction (TEI '18). ACM, New York, NY, USA, pp. 517-520. DOI: https://doi.org/10.1145/3173225.3173300

Kornicki, P. (2012) THE HYAKUMANTŌ DARANI AND THE ORIGINS OF PRINTING IN EIGHTHCENTURY JAPAN. International Journal of Asian Studies, 9(1), 43-70. DOI: $10.1017 / S 1479591411000180$

Moholy-Nagy, L. (1923/1989). New Plasticism in Music. Possibilities of the Gramophone. In Broken Music: Artists' Recordworks, Ursula Block and Michael Glasmeier (Eds.). Berliner Kunstlerprogramm des Daad and gelbe Musik, Berlin, Germany, pp. 53-58.

Oord, A. V. D., Dieleman, S., Zen, H., Simonyan, K., Vinyals, O., Graves, A., ... \& Kavukcuoglu, K. (2016). Wavenet: A generative model for raw audio. arXiv preprint arXiv:1609.03499.

Seiffarth, C. and Beirer, I. (2011) Buried in Noise, Kehrer Verlag, pp. 127-139.

Sterne, J. (2003). The audible past: Cultural origins of sound reproduction. Duke University Press.

Thompson, M. (2017). Beyond unwanted sound: noise, affect and aesthetic moralism. Bloomsbury Publishing USA. 